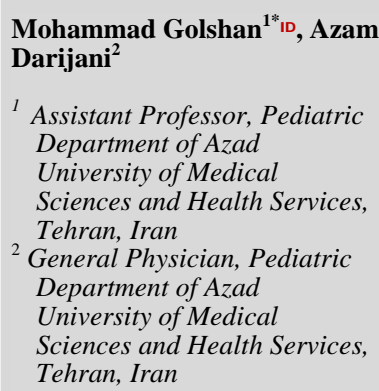

*Corresponding Author: Pediatric Department of Azad

\section{Salt Powder in Management of Umbilical Granuloma: A Randomized Trial Study}

Received:22 Dec. 2017; Accepted: 2 May 2018

\section{Abstract}

Background: Alcohol, antibiotic ointments, silver nitrate and ligation had been presented for treatment of umbilical granuloma. Salt powder due to its hyper osmolarity effects can induce drying and necrosis of granuloma tissue. Present parallel single blind randomized clinical trial was performed in neonates of shahvali hospital for assessment of salt powder in management of umbilical granuloma.

Patients and Methods: Present parallel single blinded randomized clinical trial was performed on 60 neonates with umbilical granuloma between January and October 2015. Our samples were selected randomly from neonates with healthy umbilical granuloma. Neonates in case group, salt powder was prescribed in five days (30 minutes two times per day) and located on the umbilical granuloma. During these five days neonates in control group were only clinically examined. Complete removal of umbilical granuloma was considered as study outcome.

Results: Umbilical granuloma removed in all neonates of case group who were treated with salt powder but in control group, only four neonates had complete granuloma removing. Recovery rate had significant difference between two trial groups $(p=0.00)$.

Conclusion: Management of umbilical granuloma with salt powder in neonates had suitable therapeutic effects in comparison with other methods without any complications.

Keywords: Umbilical granuloma, Salt powder, Neonates, Complication 


\section{استفاده از يودر نمك در درمان كرانولوم نافى: يك مطالعه كارآزمايى تصادفى}

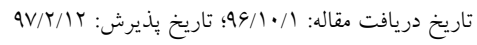

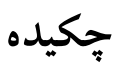

مقدمه: الكل، يماد آنتى بيوتيك، نيترات نقره و مسدودسازى روشهاى درمان كرانولوم نافى هستند. يودر نمك بو اسططه اثـر

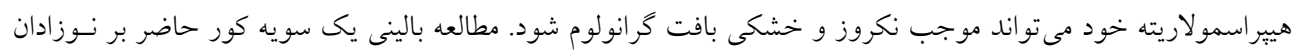

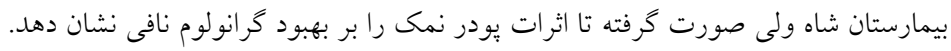

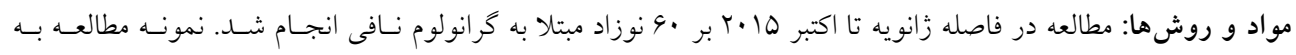

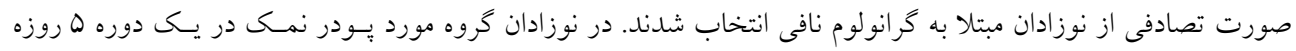

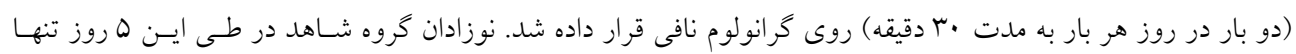

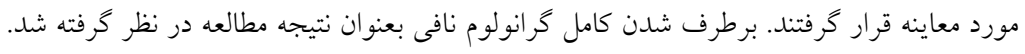

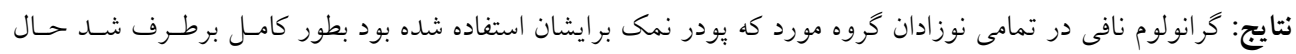

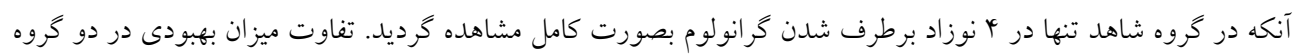

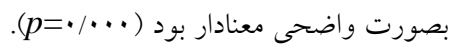

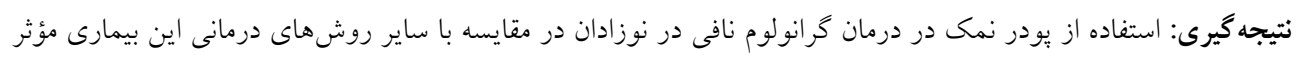
و بدون عارضه است.

كلمات كليدى: گر انولوم نافى، يودر نمك، نوزادان، عوارض

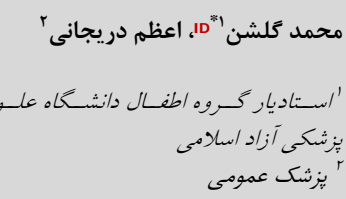

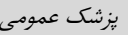

نويسنده مسئول:

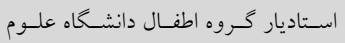
بز شكى آزاد اسلامى

- १1r-rQTqRTr

E-mail: mgolshan035@gmail.com 
ه ا ب انجام شد. مطالعه حاضر بعد از دريافت مجوز اخلاق دانشگاه

آزاد اسلامى با دريافت رضايت از والدين نوزادان آغاز شد. نمونهها از ميان نــوزادان مبـتلا بـهـ كرانولـوم نـافى كـه بـهـ درمانحــاه اطفــال بيمارستان مراجعه كرده بو دند به صورت تصادفى انتخاب شدند. اين

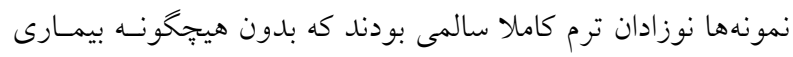

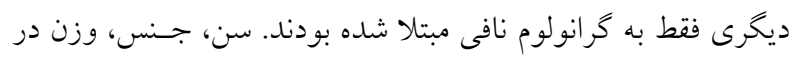
زمان تولد و مشخصات ديخر در جـى ليست ثبت گرديد.

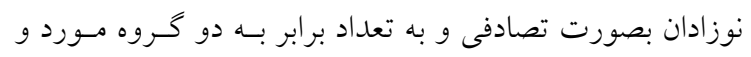
شاهد براساس جدول اعداد تصادفى تقسيم شـدند و سـن و جــس

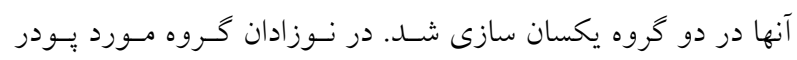

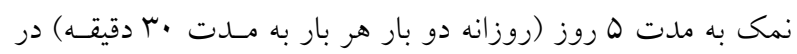
محل گرانولوم نافى قرار گرفت، در طول ها روز يـاد شــده نــوزادان كروه شاهد تنها مورد معاينه قرار گرفتند. عوارض كرانولوم نافى در طى اين ه روز در هر دو گروه مورد بررسى قـرار گرفـت. برطـرف

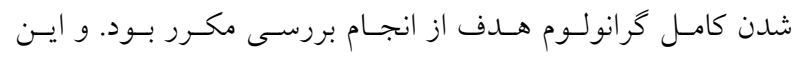

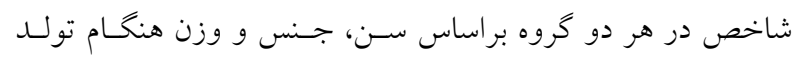
مورد تحليل قرار گرفت. بعد از پِيان مطالعه نوزادان گروه شاهد نيز مورد درمان با يودر نمك قرار كرفتند و بهبودى كامل براى آنان نيـز در مدت ه روز بعد حاصل گرديد.

\section{تحليل آمارى}

دادهها با نرمافزار SPSS ورزن 19 تحليل شدند. متغيرهاى كمى با اندازه گيرى شـاخص هـاى مركـزى (ميـانخين و انحـراف معيـار) متغيرهاى كيفى با جداول شيوع (شيوع و درصد) و متغيرهاى كمسى

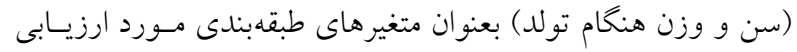

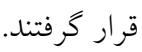
جدول ا: مقايسه palue و ميانحين متغيرهاى بايه (سن، جنس و وزن هنگام تولد) در دو گروه مورد و شاهد در نوزادان بيمارستان شاه ولى يزد از زانويه تا اكتبر

\begin{tabular}{|c|c|c|c|}
\hline$p$ value & كروه شاهد (mean+SD) & كروه مورد (mean \pm (mD) & مطالعه گروه \\
\hline NS & $\mu \cdot(\% / . \cdot)$ & $\mu \cdot(\% / .0 \cdot)$ & جنس (تعداد و درصد) \\
\hline NS & $r \mu / \cdot r \pm 9 / \cdot r$ & $Y Y / \Psi \pm \Lambda / Q Y$ & سن (روز) \\
\hline NS & $r 909 \pm \Delta / r V$ & $r \wedge F \mid \pm q / Y$. & وزن هنگام تولد (گرم) \\
\hline
\end{tabular}

در طى مطالعه VY نوزاد نمونه به تحقيق اضافه شده و از تحقيق حذف شدند (9 نوزاد شرايط مطالعه را نداشتند و والـدين

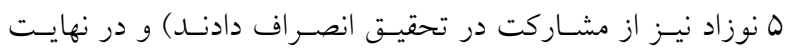

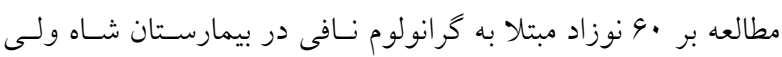

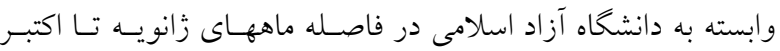
درباره نحوه درمانى گرانولوم نافى مطالعات اندكى وجود دارد و اغلب آنها از برجسب نيترات نقره بعنوان درمان مؤثر اين عارضه ياد

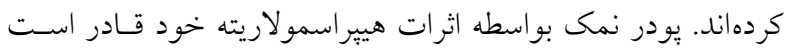
موجب خشكى و نكروز بافت كرانولاسيون شود. مطالعه حاضر كـه به روش كارآزمايى بالينى تصادفى شــه يـك سـويه كـور صـورت كرفته استفاده از يودر نمك را در درمان گرانولوم نـافى در نـوزادان بيمارستان شاه ولى مورد بررسى قرار مىدهد.

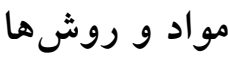

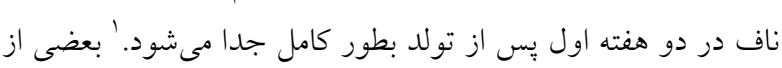
فرآيندهاى باتولوزيك مثل عفونت و التهاب مى توانند باعث تشكيل

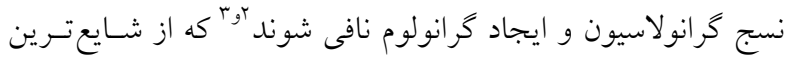

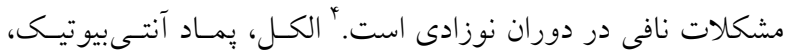

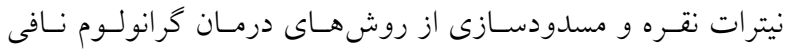

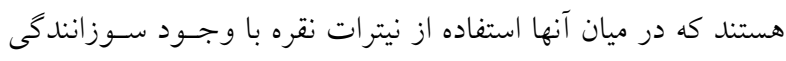

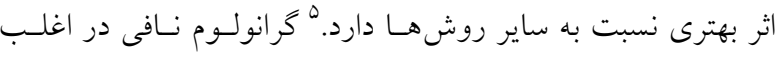

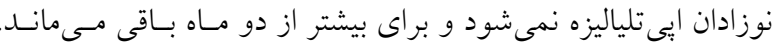

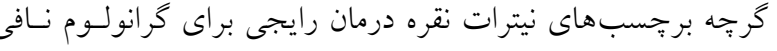
نيترات نقره است. 
درصد درمان كامل داشتند.

در نوزادان يرهترم نيز ميزان بهبودى در دو گروه مورد و شاهد به

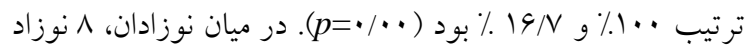

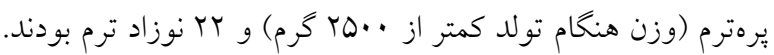

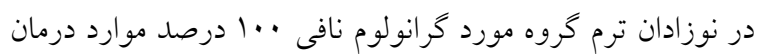

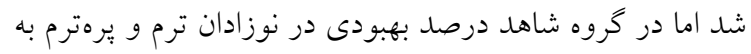
ترتيب 1 1 1 \% و 19/V ٪ بود كه تفاوت معنى دارى را نشان مىداد

$(p=\bullet \cdot \cdots)$

\section{بحث}

با اين مطالعه تصادفى يكسويه كـور دريـافتيم كـه يـودر نمـك

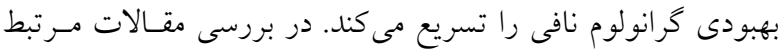
مشخص شد كه مطالعات بسيار محدودى در اين مورد انجام گرفتسه است. اشميت نخستين كسى بود كـه اتـرات قـابض يـودر نمـك را

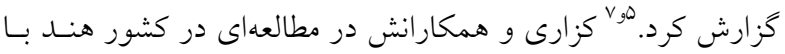

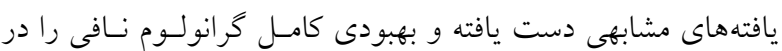

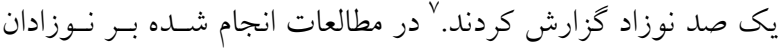
ايران سه مطالعه با الخوهاى ابيدميولوزيك متفاوت ييدا كرديم كه در

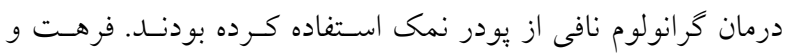

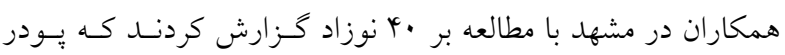

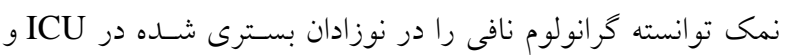
نوزادان مراجعه كننده به درمانگاهها بطور كامل درمان كنــ. در ايسن مطالعه استفاده از يودر نمك در دو بازه زمـانى دو سـاعته و روزانـه.

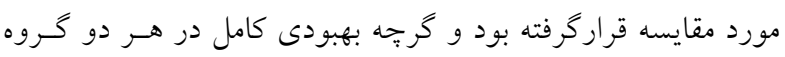
مشاهده شد اما در كروهى كه روزانه از يودر نمكى استفاده مى كردند نتايج بهترى داشت. فرهنوش و همكاران در مطالعه ديخرى بر هـا نوزاد اثرات الكل

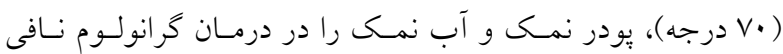
مقايسه كردند و به اين نتيجه رسيدند كه كرجه آب نمك والكل نيسز

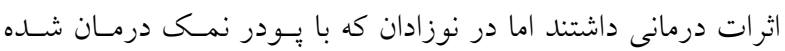

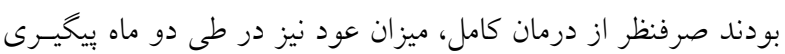

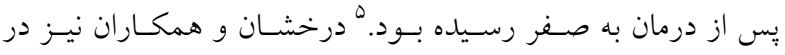

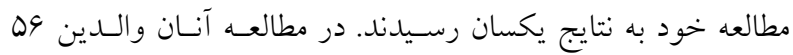

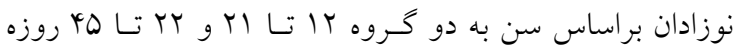
تقسيم شدند و يافته هاى مطالعه بعنوان متغير كيفى بـين نـوزادان دو كُروه براساس سن، جنس و وزن تولد به روش كاى اسـكوير مـورد تحليل قرار گرفتند. حد معنى دار بودن براى بررسى تفـاوتهــاى دو كروه ه• • • در نظر گرفته شد.

\section{نتايج} در طول مطالعه VY نوزاد وارد مطالعه شده و با نوزاد از مطالعه . خارج شدند، دست آخر مطالعه بر •ونوزاد انجام شـد، در بررسى متغيرهاى دو گروه شيوع جنس در دو گروه يكسان در نظـر گرفتسه

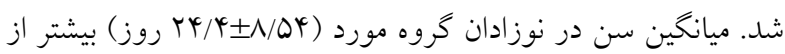

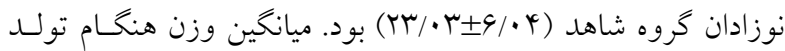
در گروه شاهد (YN/TVI

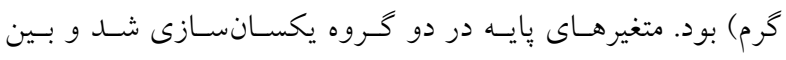

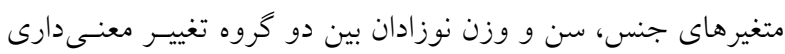

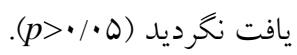
كرانولوم نافى در تمام نوزادان گروه مــورد بـا اسـتفاده از يــودر

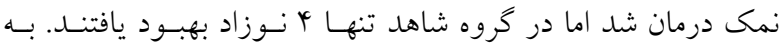
عبارت ديخر ميزان بهبودى در دو حـروه بطـور معنسى دارى تفـاوت داشت ( • (

كرانولوم نافى در تمام يسران و دختران گرووه مورد درمــان شـــ اما در كروه شاهد ميزان بهبـودى در يسـران و دختـران بـهـ ترتيـبـ

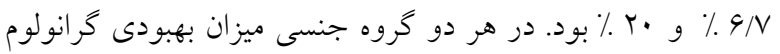
نافى در گروه مورد بيشتر از گروه شاهد و اين اختلاف معنى دار بود ج) كروه مورد كامل بود اما اين ميزان در دو دسـته يـاد شــده در خـروه

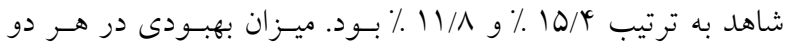
كروه سنى در گروه مورد به طرز معنىدارى از گروه شاهد بالاتر بود

$$
\text { . }(p=\cdot \cdots)
$$

تمام نوزادان كم وزن گروه مورد بطور كامل درمان شدند اما در

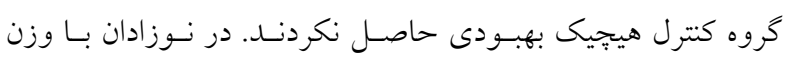

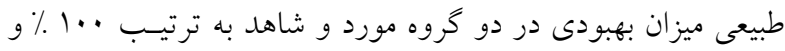

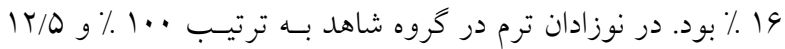


خاطرنشان مى كند كه استفاده از يودر نمك در درمان گرانولوم نـافى

در نوزادان در مقايسه با ساير روشهاى درمانى مؤثر و بدون عارضه دئه

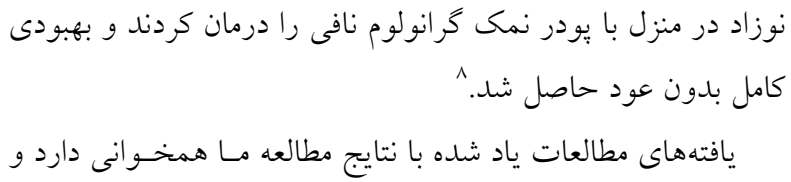

\section{References}

1. Wilson CB, Ochs HD, Almquist J, Dassel S, Mauseth R, Ochs UH. When is umbilical cord separation delayed? J Pediatr. 1985 Aug;107(2):292-4.

2. Nagar H. Umbilical granuloma: a new approach to an old problem. Pediatr Surg Int. 2001 Sep;17(7):513-4.

3. Rowe M, Oniel J, Grosfeld J, Fonklasrud E, Coran A. Disorder of umblicus. Essential of pediatric surgery. New York Mosby; 1995. p. 441-5.

4. Farhat A. Newborn umbilical granuloma treatment with salt. . Med journal of Mashhad university of medical science 2000;43(67):105-8.[In Persian]
5. Faranoush M, Ghorbani R, Malek M, Aminbidokhti M, Yazdiha M. A compriative study on therapeutic effect of sodium choloride and alcohol in infants with umbilical granuloma. Ghazvin university of medical science. 2006;10(2):65-8.[In Persian]

6. O'Donnell KA, Glick PL, Caty MG. Pediatric umbilical problems. Pediatr Clin North Am. 1998 Aug;45(4):791-9.

7. Kesaree N, Babu PS, Banapurmath CR, Krishnamurthy SN. Umbilical granuloma. Indian Pediatr. 1983 Sep;20(9):690-2.

8. Derakhshan M. curative effect of common salt on umblical granuloma. Iranian journal of medical science 1998;23:132-3. 